\title{
VELOCITY DISTRIBUTION IN CHANNELS INFESTED BY SUBMERGED WEEDS
}

Gamal M. Abdel-aal, Amany A. Habib, Abd-elazeem M. Ali, Marwa F. Shaheen

\begin{abstract}
Existence of weeds in irrigation channels causes many serious problems such as velocity reduction, increas levels, and prevents water from reaching the canal end. So aquatic weeds have to be controlled to an acce to improve the channels performance. The present paper aims to study experimentally the velocity distribi channels with the presence of submerged weeds in case of maintaining the water levels behind the infeste data were collected using a laboratory flume in the hydraulic laboratory of the Hydraulic Research Institut $\epsilon$ sponsored by the National Water Research Center (NWRC). The flume of relatively large dimensions (60cm depth, and $20.8 \mathrm{~m}$ long) and fixed bed slope (0.0062). Flexible plastic branched roughness elements were different intensities ( $\mathrm{Is}=0.0062,0.0123$, and 0.0246 ). The weeds intensities were tested with different di different tail water depths. Dimensionless general equation in terms of the flow and weeds parameters for average velocity was developed and compared with the experimental data. The comparison proved a good and high accuracy
\end{abstract}

